\title{
Voltage Collapse Avoidance by using STATCOM
}

\author{
Champa Nandi \\ Assistant Professor \\ Dept. of Electrical Engineering \\ Tripura University
}

\author{
Jhuma Rudra Pal, Tandra Sutradhar. \\ Dept. of M.Tech Electrical Engineering \\ T.U. (A Central University)
}

\begin{abstract}
This paper deals with modelling and simulation of STATCOM in IEEE 14 bus System with Induction Motor load for avoiding voltage collapse. Three Phases to ground fault is applied in predominant Induction motor load bus for voltage collapse analysis. The effect of Critical Fault Clearing Time [CFCT] of the system due to facing the fault, to prevent permanent voltage collapse has been analyzed with and without STATCOM. Simulations of the STATCOM were carried out by using Power System Computer Aided Design (PSCAD) software. Simulation results prove that the STATCOM is capable of mitigating voltage collapse with minimum clearing Time.
\end{abstract}

\section{Keywords}

STATCOM; Reactive power compensation; Voltage Collapse;CFCT;Stability.

\section{INTRODUCTION}

Modern power systems are designed so as to improve the performance of an ac power system. We need to manage this reactive power in an efficient way and this is known as reactive power compensation. Two aspects to the problem of reactive power compensation are : load compensation and voltage support. Load compensation consists of improvement in power factor, balancing of real power drawn from the supply, better voltage regulation. Voltage support consists of reduction of voltage fluctuation at a given terminal of the transmission line. Two types of compensation can be used: series and shunt compensation. The jobs of absorbing or generating reactive power with a faster time response come under Flexible AC Systems (FACTS).An increase in transfer of apparent power through a transmission line, and much better stability by the adjustment of parameters that govern the power system i.e. current, voltage, phase angle, frequency and impedance. It is essential to balance the supply and demand of Active and Reactive power in a power system. If the balance is lost the system frequency and voltage excursion may occur resulting, in worst case, in the collapse of the power system. The increase in the loading of the transmission lines in power systems sometimes can lead to voltage collapse due to the shortage of reactive power delivered at the load centers. Appropriate voltage and reactive power control is one of the most important factors for stable power system operation. FACTS devices can make the AC transmission network 'flexible' to adapt to the changing conditions caused by these contingencies and load variations. Flexible AC Transmission System (FACTS) according to IEEE is defined as, "Alternating current transmission systems incorporating power electronic-based and other static Controllers to enhance controllability and increase power transfer capability" There are two generations for realization of power electronics based FACTS controllers: the first generation employs conventional thyristor-switched capacitors and reactors, and quadrature tapchanging transformers, the second generation employs gate turn-off (GTO) thyristor-switched converters as voltage source converters (VSCs) Static Synchronous Compensator (STATCOM). STATCOM is one of the advanced technologies of power electronics system known as FACTs Controller, which provides fast and continuous capacitive and inductive reactive power supply to the power system.[1][2][3]

\section{STATCOM}

Static Synchronous Compensator (STATCOM) is the second generation of FACTS controllers that has a very promising future application. A Static Compensator consists basically a step down transformer with a leakage reactance, a phase GTO voltage source converter of a voltage source converter and a DC capacitor, a coupling transformer and controls. When the converter voltage (VD) is lower than the bus voltage (VB) the STATCOM acts like an inductance absorbing reactive power from the bus. When the converter voltage (VD) is higher than the bus voltage (VB), the STATCOM acts like a capacitor generating reactive power to the bus.

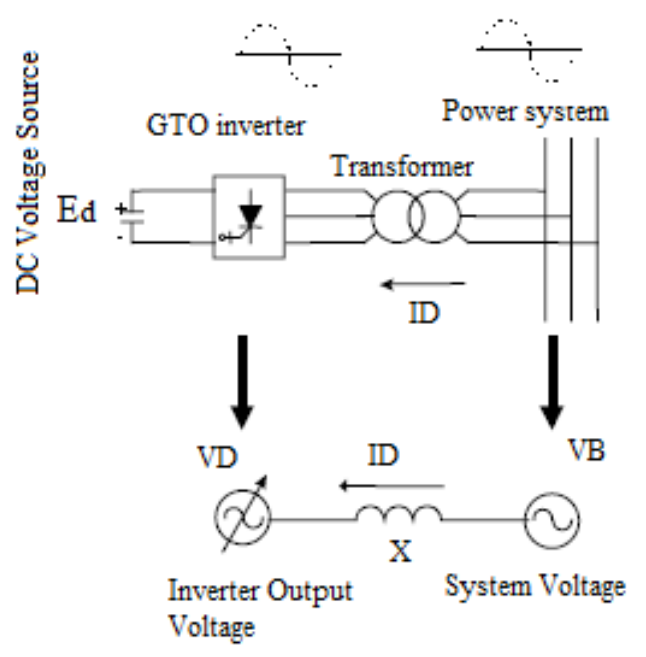

Fig 1: STATCOM basic Configuration. 


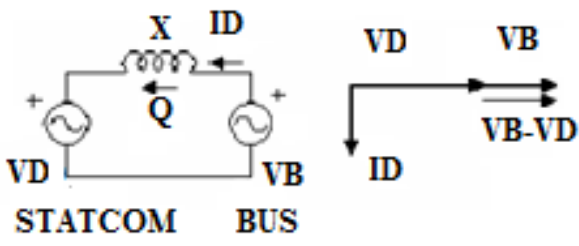

Fig 2: Inductive operation.

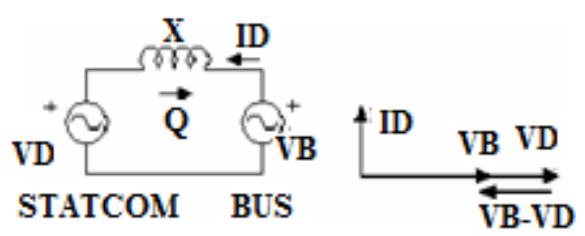

Fig 3: Capacitive operation.

During No load mode, VB $=\mathrm{VD}, \mathrm{ID}=0$. The reactive power is zero and the D-STATCOM does not generate or absorb reactive power.

During Inductive mode of Operation ID appears to be lagging current, since the magnitude of the current can be controlled by adjusting VD. The STATCOM will function as a reactor whose inductive reactance is continuously controllable. The current (ID) flows through the transformer reactance from the AC system to STATCOM device. The device generates Inductive reactive power.

During Capacitive mode of Operation ID appears to be leading current, Since the magnitude of the current can be controlled by adjusting VD. The STATCOM will function as a capacitor whose capacitive reactance is continuously controllable. The current (ID) flows through the transformer reactance from STATCOM device to the AC system. The device generates capacitive reactive power. [1][4]

In an inductive circuit, we know the instantaneous power to

be $\mathrm{P}=I \max V \max \cos \omega t \cos (\omega t-\theta)$.

$\mathrm{P}=\frac{I \max V \max }{2} \cos \theta(1+\cos 2 \omega t)+$

$\frac{I \max V \max }{2} \sin \theta \sin 2 \omega \mathrm{t}$.

Instantaneous power is

$$
\frac{\text { VmaxImax } \operatorname{Sin} \theta \operatorname{Sin} 2 \omega \mathrm{t}}{2}
$$

Where, $\quad V \max =$ Peak value of the voltage waveform; Imax $=$ Peak value of the current waveform; $\omega=$ Angular frequency $=2 \pi f$, where $\mathrm{f}$ is the frequency of the waveform; $\mathrm{t}=$ Time period; $\theta=$ Angle by which the current lags the voltage in phase.

\section{CONTROLLER CONFIGURATION}

Measured reactive power and root mean square (RMS) voltage (in per unit) is given as the input. The measured reactive power is divided with the rated reactive power of the circuit. This output is divided with the measured RMS voltage (in per unit). After allowing a drop of about 3\% the output of this block is summed up again with the Measured RMS voltage .This summed output is passed through filters. The reference voltage (in per unit), is summed with the output signal of the filters. This is given as input to the PI controller. The output of PI controller is the angle order. It represents the required shift between system voltage and voltage generated by shunt converter (STATCOM). This shift determines the output angle order is converted to degrees. Firing signals are generated by pulse width modulation technique. The instantaneous voltage measured is split into its 3-phase components. This is given as input to the 3-phase PI controlled phase locked loop. It generates a ramp signal that is synchronized in phase to the input voltage signal. This is then multiplied with a real constant to obtain the necessary carrier frequency. From this triangular waveforms synchronized with system AC voltage are generated. Now sinusoidal waveforms synchronized with system AC voltage and shifted by the angle order are to be generated. Again, the instantaneous voltage split into its 3-phase components is given as input to the 3phase PI controlled phase locked loop. The generated signal that is synchronized in phase to the input voltage signal is shifted by the obtained angle order. Then, this output signal is sent to the sinusoidal function block to generate the required sinusoidal waveforms. The generated triangular and sinusoidal waveforms are sent to the interpolated firing pulse generation block. Two sets of input signals (reference and triangular ones) are needed; one set for turning on and the second one (a negation of the first set of signals) for turning off. Firing pulses are generated using comparison of sinusoidal signals to triangular signals. The output signals generated are of two element arrays. The first element determines the firing signals which indicate the gate turn-off (GTOs) to turn-on and turn-off. The second element determines the exact moment of switching which is used by interpolation procedure for switching between time steps. [6][7] 


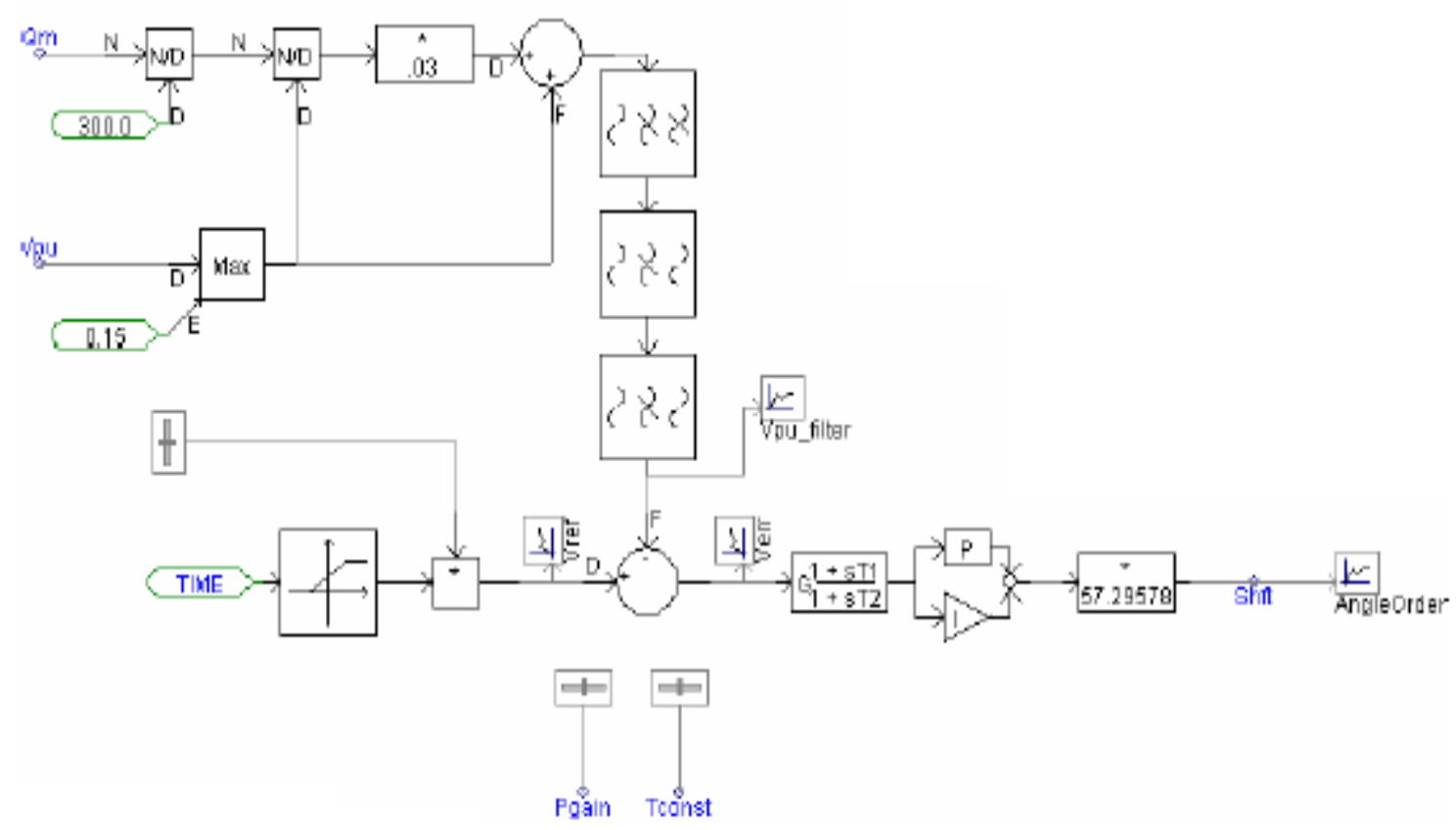

Fig 4: Reactive Power Control Loop.

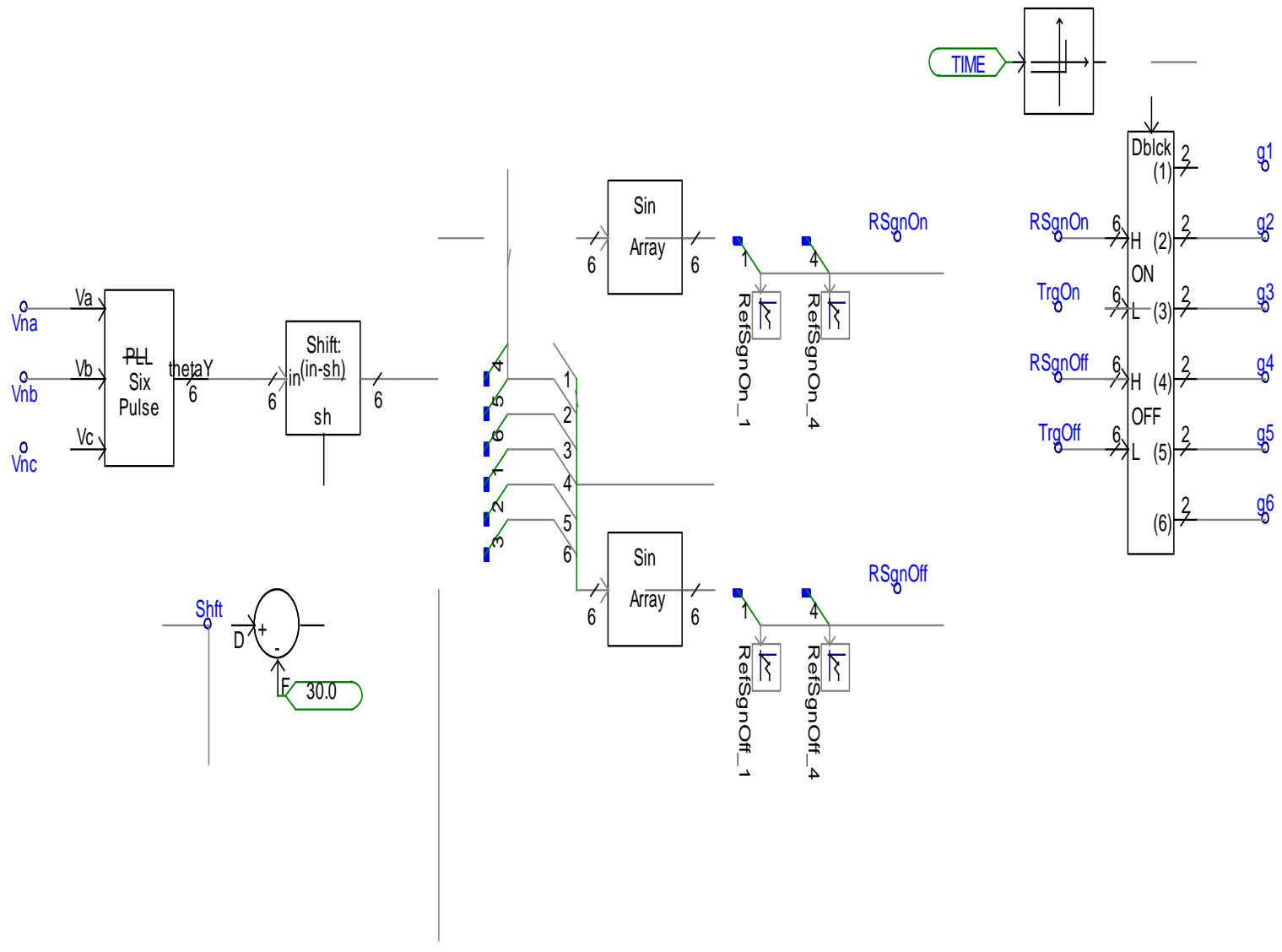

Fig 5: Generation of Reference Sine Wave 


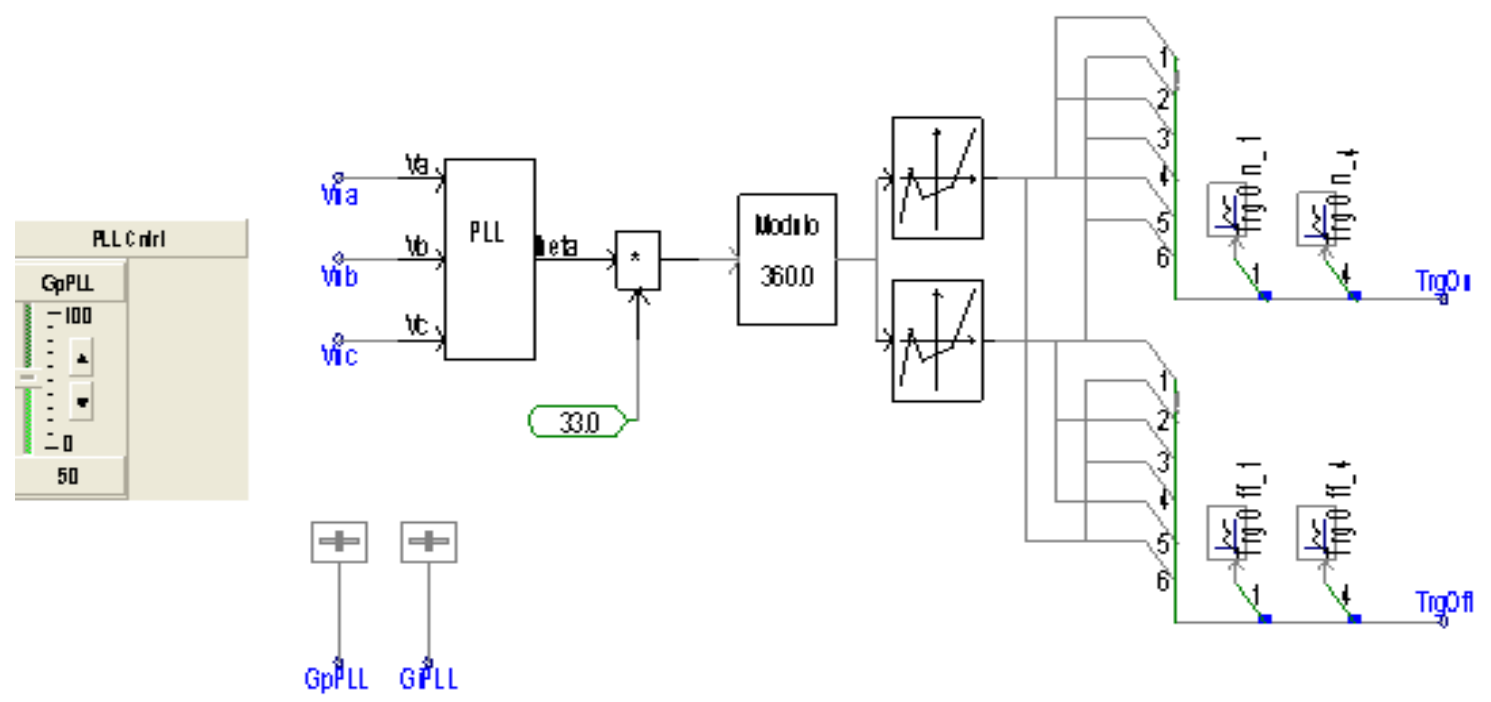

Fig 6: PWM carrier generation.

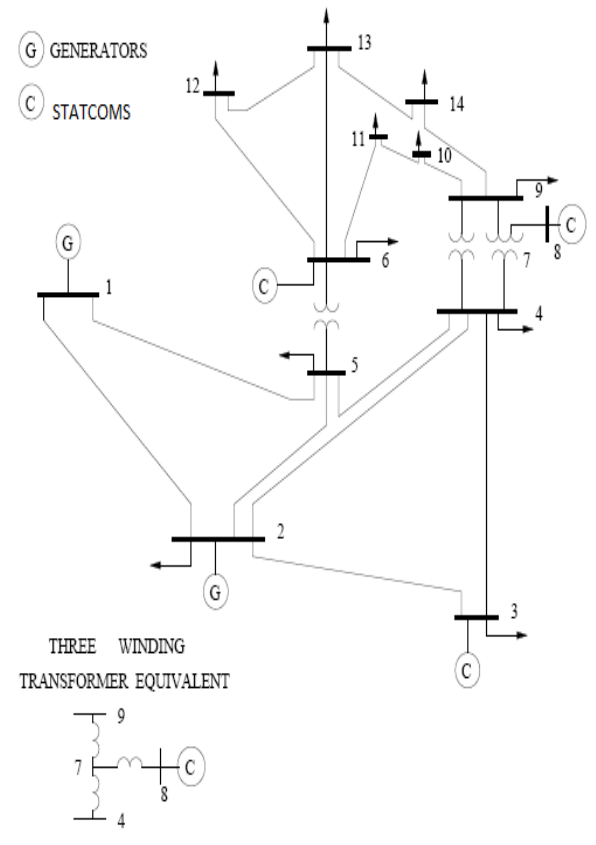

Fig 7: IEEE 14 bus system with interconnected STATCOM compensator.

\section{SIMUILATION AND DESCRIPTION}

An IEEE 14-bus test system as shown in figure 7 is used for voltage stability studies. The test system consists of 2 Generators and 11 load buses. A single line diagram of the IEEE 14-bus standard system extracted from is shown in Figure 7. There are three Static Synchronous Compensators used in Bus 3, Bus 6, and Bus 8. An Induction motor of $74.6 \mathrm{KW}$ is connected to bus 6 for improving the power system performance. Three-phase to ground fault is applied close to the Induction motor for collapse case study. The control of the STATCOM voltage magnitude should be such that the specified bus voltage and the STATCOM voltage should be equivalent and there should be no difference between them. The PI controller process the error signal and generates the required angle $\delta$ to drive the error to zero, i.e., the load rms voltage is brought back to the healthy voltage level [healthy voltage level from 0.95 P.U to 1.05 P.U. 


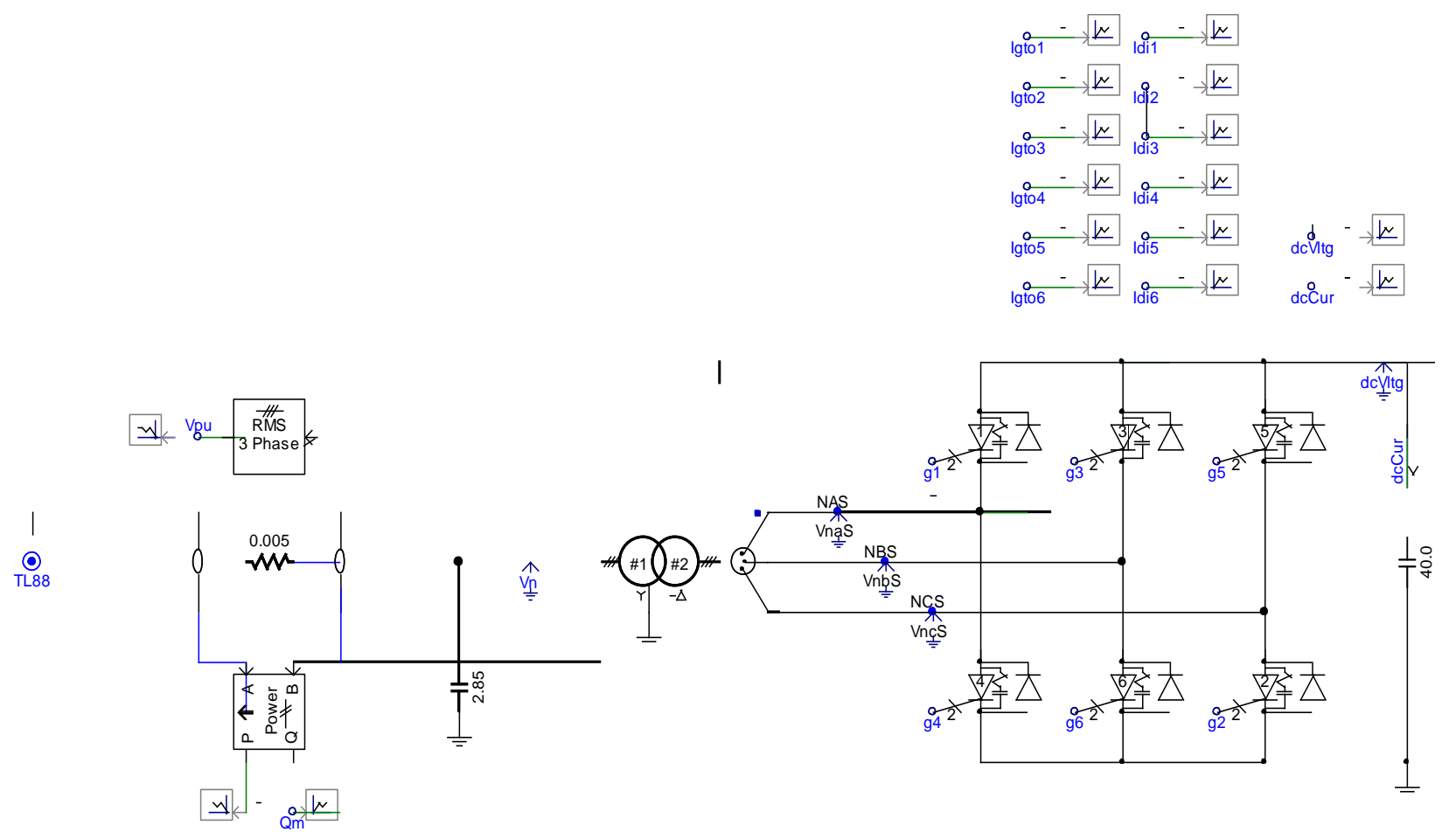

Fig 8: STATCOM device in PSCAD/EMTDC environment.

\section{RESULTS AND DISCUSSION OF RESULTS}

\subsection{Angle Order}

The output of PI controller is the angle order, which is used to maintain the phase shift. The reactive power flow from the system is compared to the reference per-unit voltage that contributes to a change of the phase shift. The difference in phase shift will provide the needed reactive power from the DC capacitor.

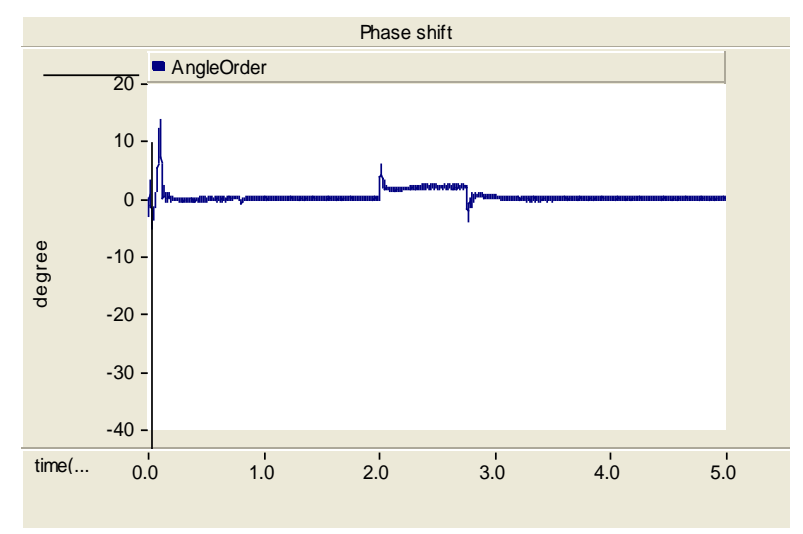

Fig 9: Generation of Angle order

\subsection{Compensated Reactive Power}

At the distribution level, it is used to improve the power factor and support the voltage of large industrial loads. This is particularly crucial in situations where some fault appears in the grid. In such a situation, it will often be a matter of milliseconds for the Reactive Power Compensator, i.e. the FACTS device, to go into action and help restore the stability, and the voltage of the grid, in order to prevent, or mitigate, a voltage collapse.

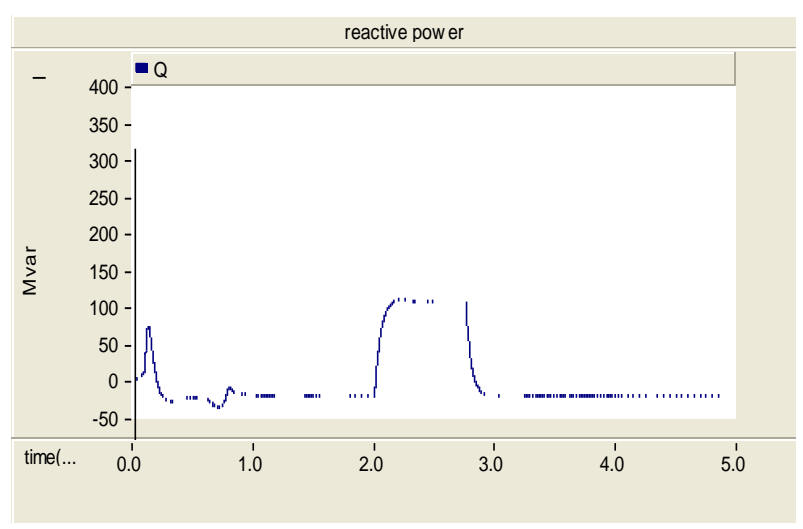

Fig 10: Reactive power output. 


\subsection{Voltage Collapse Case}

Table: Comparative Voltage Level (at Bus 6) of IEEE 14 Bus Systems

\begin{tabular}{|c|c|c|c|c|}
\hline $\begin{array}{l}\text { SL } \\
\text { no }\end{array}$ & $\begin{array}{l}\text { System } \\
\text { Condition }\end{array}$ & $\begin{array}{l}\text { Time } \\
\text { (sec) }\end{array}$ & $\begin{array}{c}\text { Voltage } \\
\text { level with } \\
\text { STATCOM } \\
\text { (p.u) }\end{array}$ & $\begin{array}{c}\text { Voltage level } \\
\text { Without } \\
\text { STATCOM } \\
\text { (p.u) }\end{array}$ \\
\hline 1. & \multirow{4}{*}{$\begin{array}{l}\text { Before } \\
\text { Fault } \\
\text { (Healthy } \\
\text { Condition) }\end{array}$} & 0.0 & 0.0 & 0.0 \\
\hline 2. & & 0.5 & 1.00 & 1.04 \\
\hline 3. & & 1.0 & 0.99 & 1.03 \\
\hline 4. & & 1.5 & 1.00 & 1.02 \\
\hline 5. & \multirow{3}{*}{$\begin{array}{c}\text { Faulty } \\
\text { Condition } \\
\text { (3-Phase } \\
\text { to Ground } \\
\text { Fault) }\end{array}$} & 2.0 & 0.99 & 1.01 \\
\hline 6. & & 2.5 & 0.99 & 0.78 \\
\hline 7. & & 2.75 & 0.99 & 0.75 \\
\hline 8. & \multirow{9}{*}{$\begin{array}{c}\text { After } \\
\text { Fault } \\
\text { Removal }\end{array}$} & 2.775 & 1.03 & 0.83 \\
\hline 9. & & 2.8 & 1.01 & 0.83 \\
\hline 10. & & 2.825 & 1.00 & 0.832 \\
\hline 11. & & 2.85 & 1.00 & 0.825 \\
\hline 12. & & 3.0 & 1.00 & 0.828 \\
\hline 13. & & 3.5 & 0.99 & 0.82 \\
\hline 14. & & 4.0 & 1.00 & 0.81 \\
\hline 15. & & 4.5 & 1.00 & 0.81 \\
\hline 16. & & 5.0 & 1.00 & 0.8072 \\
\hline
\end{tabular}

The main symptoms of voltage collapse are - low voltage profiles, heavy reactive power flows, inadequate reactive support, and heavily loaded systems. it is seen that without FACTS controllers the voltage level enters in voltage instability zone even if the fault is cleared. But due to presence of a STATCOM this type of instability can be avoided.

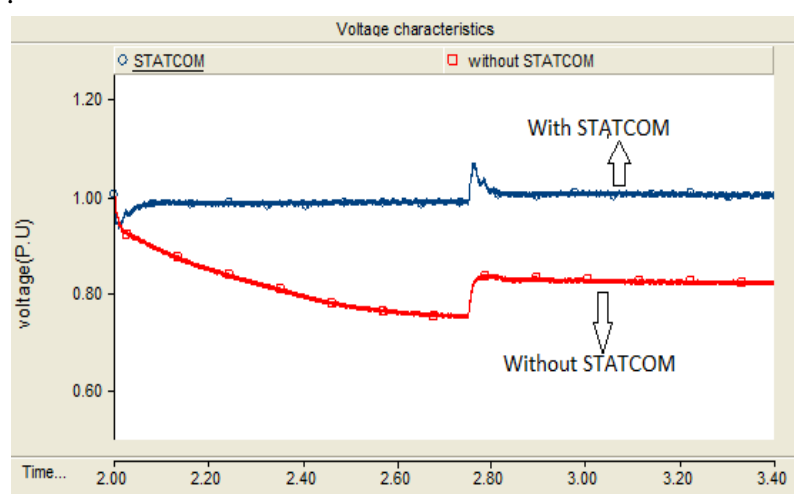

Fig 11: Voltage characteristics graphs during voltage collapse

\subsection{Critical Fault Clearing Time [CFCT]}

It is cleared that the critical fault clearing time is important to ensure stable operating voltage for the Induction Motor predominant load buses. The critical clearing time for the system to regain voltage at stable state

5.2.1 With the Presence of STATCOM is $46 \mathrm{msec}$.

5.2.2 Without the STATCOM the system have not comes back to its original operating voltage level.[9]

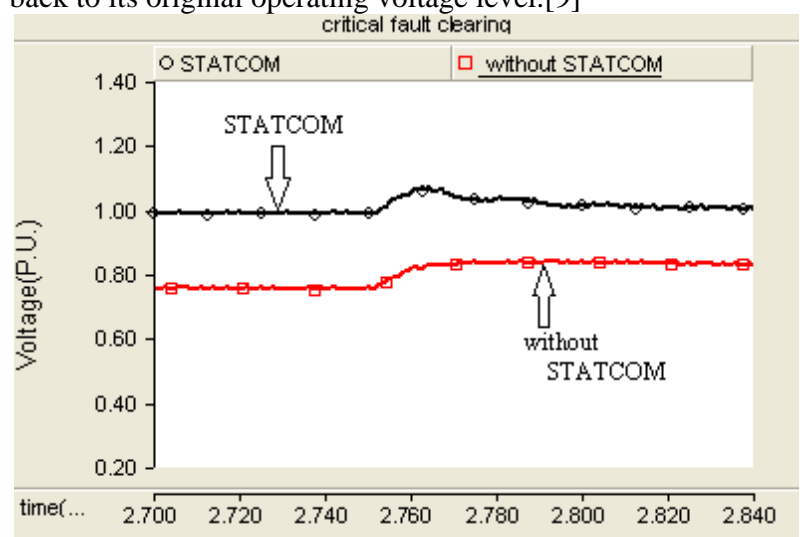

Fig 12: Voltage characteristics graphs during voltage collapse

\section{CONCLUSION}

The control strategy for the STATCOM is the AC side voltage or reactive power control. The IGBT's are connected inversely and parallel to the diodes for commutation purposes and to charge the capacitor. IGBTs are used in this simulation because it is easy to control the switch on and off of their gates and suitable for the designed STATCOM. From the simulation results, the construction designed STATCOM responded well in mitigating voltage collapse caused by threephase balanced fault. The DC capacitor value is dependent on the percentage of voltage sag. The difference of step drop load current during sag is the amount of reactive current needed to be compensated. Hence STATCOM is a promising device in power systems for mitigating power quality related problems. 


\section{REFERENCES}

[1] Abu-Siada, Chatura Karunar, "Improvement Of Transmission Line Power Transfer Capability, Case Study", Electrical and Electronics Engineering: An International Journal (EEEIJ) Vol.1, No.1, May 2012.

[2] Hendri Masdi, Norman Mariun, S.M. Bashi, Azah Mohamed, Sallehhudin Yusuf," Construction of a Prototype D-Statcom for Voltage Sag Mitigation "European Journal of Scientific Research ,ISSN 1450216X Vol.30 No.1 (2009), pp.112-127

[3] S.HADJERI, Fatiha GHEZAL ,S.A.ZIDI, "Simulation of a three level 48 pulses Statcom " 2008-Mediamira science Publisher. Volume 49, Number 2, 2008.

[4] S.H. Hosseini, R. Rahnavard, Y. Ebrahimi, "Reactive Power Compensation in Distribution Networks with STATCOM by Fuzzy logic Theory Application", $5^{\text {th }}$ International Power Electronics and Motion Control
Conference (IPEMC), Shanghai, China, 14-16August 2006 (CD).

[5] S.H. Hosseini, R. Rahnavard, "Comparison of Two Methods for Shunt Active Power Filter under the Distorted Source Voltages Condition” ,ECTI-CON, Rachthani, Thailand, pp. 9-13, Rachthani, 10-13 May 2006.

[6] S.Sundeep, Dr. G. Madhusudhana Rao," Modelling and Analysis of Custom Power Devices for Improve Power Quality", International Journal of Electrical and Computer Engineering (IJECE),Vol.1, No.1, September 2011, pp. 43 48, ISSN: 2088-8708.

[7] Facts Modelling and Simulation in Power Networks.By.Enrique Acha,Claudio R.FuerteEsquivel,Hugo Ambriz-Perez,Cesar AngelesCamacho,(p.17,p.155-178). 